\title{
Engaging patients through Multi-Disciplinary Rounding - The case study at a Michigan hospital
}

\author{
Bryan L. Fowler ${ }^{1}$, Julie Johns ${ }^{2}$, Mohan R. Tanniru*3, Venugopal Balijepally ${ }^{3}$, Yazan F. Roumani ${ }^{3}$, David Bobryk ${ }^{4}$, \\ Karen Mitchell ${ }^{3}$ \\ ${ }^{1}$ Patient Experience Specialist, Pontiac, MI, United States \\ ${ }^{2}$ Director, Care Experience, Henry Ford Wyandotte Hospital, Detroit, MI, United States \\ ${ }^{3}$ Oakland University, Rochester, MI, United States \\ ${ }^{4}$ Clinical Informatics, Pontiac, MI, United States
}

Received: April 13, 2018

DOI: $10.5430 /$ jha.v7n5p17
Accepted: June 25, 2018

Online Published: July 10, 2018

\begin{abstract}
Multi-Disciplinary Rounding (MDR) is a leading practice and a promising process innovation that seeks to enhance both patient experiences and healthcare outcomes for hospitals. It requires multiple hospital staff involved in patientcare visiting patients as a team at their bedside, so that they can address various issues related to patientcare and care transition and answer any patient questions. This paper discusses the implementation of two different models of patient engagement through MDR to gain input from patients while they are still in the hospital, as opposed to relying on patient satisfaction data, so that hospitals can alter their strategies to educate patients on care plans and help empower them to self-manage their care post-discharge. The MDR is implemented as a process innovation at a comprehensive community teaching hospital in Michigan, with the expectation that it can lead to improved organizational outcomes in both the short run (e.g., reduced length of stay [LOS]) and the long run (e.g., reduced patient readmission and improved patient satisfaction). The hospital implemented MDR in various units as a process innovation to improve patient engagement and patient satisfaction. The initial phase of MDR implementation was nurse-led to gain feedback from patients at three time periods (30,60 and 90 days) on patient services. The hospital revised the MDR process in the second phase into a doctor-led patient education process. While the results to date are not conclusive, they do show how MDR can be used by hospitals to engage patients inside the hospital to gain feedback for continuous improvement, using technology when appropriate, and support patient education on care plans post-discharge.
\end{abstract}

Key Words: Multi-Disciplinary Rounding, Bedside rounding, Process innovation, Patient education

\section{INTRODUCTION}

Hospitals and healthcare providers are constantly looking for ways to improve not only the clinical outcomes for patients, but also their overall experience during a hospital stay. ${ }^{[1]}$ All too often, hospitals find that although the clinical outcomes of patients seem satisfactory, patients may not be rating the qual- ity of their hospital experience highly. ${ }^{[2]}$ Several non-clinical issues could skew patient perceptions and thus their overall satisfaction levels. ${ }^{[3]}$ Such issues include: nurse/doctor communication (e.g., treatment of patients with courtesy and respect), hospital/room hygiene (e.g., cleanliness of a patient's room), food quality (e.g., taste and temperature of States.

Published by Sciedu Press 
the food), staff responsiveness (e.g., promptness in getting help to go to the bathroom), medicine administration (e.g., explanation of prescriptions), and care transition (e.g., what a patient needs to do once they leave the hospital ${ }^{[4]}$. Enhancing cooperation among different professionals holds the key to enhancing patient safety and overall quality of care. ${ }^{[5]}$ Thus, in addition to effectively managing clinical care, hospitals need to reflect and plan focused interventions that foster such cooperation and help improve patient experience and engagement in specific areas needing attention. ${ }^{[1]}$

To this end, Multi-Disciplinary Rounding (MDR), also called Inter-Disciplinary Rounding (IDR), Inter-Professional (bedside) Rounding ${ }^{[6]}$ (IPR), or Patient-Centered Bedside Rounds $(\mathrm{PCBR}),{ }^{[7]}$ is a leading practice and a promising process innovation that seeks to improve both patient experiences and healthcare outcomes for hospitals. It entails multiple hospital staff being involved in patientcare by visiting patients as a team at their bedside to address issues related to patientcare and care transition, and to answer questions patients or their relatives may have. This paper discusses the implementation and outcomes of introducing MDR at a comprehensive community hospital in Michigan.

The next section discusses some research in MDR and some of the key factors that were identified as critical for its success. Framing this as a leading practice and process innovation, the third section presents a proactive strategy that the Michigan hospital used to implement this innovation in two phases. Section four presents the results, and section five provides discussion and concluding comments.

\subsection{MDR in healthcare}

One of the 2018 national patient safety goals of the Joint Commission on Accreditation of Healthcare Organizations (JCAHO) is "to improve the effectiveness of communication among care providers". ${ }^{[8]}$ MDR is a mechanism used to bring together care providers and professionals from different functions as a team to coordinate patientcare, make joint decisions, manage responsibilities, and streamline patient communication. As the teams include professionals from multiple hospital functions, they are referred to as MDR teams at the Michigan hospital, which is the name we use in the rest of the paper. MDR fits into the current trend in the US of moving from a physician-centered healthcare delivery model to a team-based one. ${ }^{[9]}$

Traditionally, MDRs are regularly scheduled meetings (often daily) for those who are involved in the care of the same patients or management of the same unit. ${ }^{[10]}$ MDR meetings take place at the patients' bedside where patients are briefed on the status of various issues relating to their clinical care, discharge plan, and care transition. A limited version of MDR called Rapid Rounds is sometimes used in hospitals that involves care providers meeting at the nursing stations rather than at patient bedsides to coordinate patient care and discharge. ${ }^{[11]}$ Prior research alludes to several benefits from MDR implementation. For instance, MDR implementation is credited with improvements in both nurse job satisfaction and patient quality of care outcomes. ${ }^{[12]}$ Some other studies also report positive trends in the outcome measures relating to patient satisfaction. ${ }^{[13,14]}$ One of these studies used nationally validated instrument (Press-Ganey) as a part of the Hospital Consumer Assessment of Healthcare Providers and Systems (HCAHPS) survey ${ }^{[13]}$ for outcome measures, while the other study used an index based on three responses ("nurses treat you with courtesy and respect"; "nurses explain in a way you understand"; and "nurses listen carefully to you"). ${ }^{[14]}$ Both studies report patient satisfaction with nurse communication trending along the positive predicted direction, though the results were not statistically significant. Another controlled study could not find any impact of MDR on patient satisfaction with care or patient perceptions of shared decision making. ${ }^{[7]}$ Some hospitals report successfully implementing variants of MDR even in pediatric intensive care units. ${ }^{[15]}$

The key elements for multi-disciplinary collaboration include good communication, cooperation, coordination, mutual respect, leadership, and shared responsibility. ${ }^{[16]}$ Some even argue that interdisciplinary team collaboration and patient engagement are indispensable to the pursuit of any evidencebased plan of care approach for healthcare providers. ${ }^{[17,18]}$ Some best practices of MDR include constituting a team of people from pharmacy, social services, nutrition, and physical and occupational therapy/rehab that works with the nurse to get the process streamlined. MDR helps to bring the voice of the patient to the discussion and enable the nurse to fulfill her/his role in being the patient's primary advocate. ${ }^{[19]}$ Some ground rules to be followed during MDR rounds include coming to rounds prepared (knowing the patients and their needs, providing a list of needs for the hospitalist or other departments) and keeping these rounds short (1-2 minutes per patient) and focused (not engaging in sidebar conversations). Furthermore, continuous vigilance is necessary to reinforce and validate care processes. ${ }^{[20]}$

In summary, MDR is a process that moves the care discussion from staff-conference rooms to patients' bedsides and transforms the care delivery model by actively including the patient and family in daily care planning. This is not just a shift in the location where the meetings are held, but a change in the mental model of how caregivers and patients collectively address the clinical diagnosis, treatment processes, and post-discharge care needs. This is a complex process change 
for several reasons, including the language used in the communication, the time expended, and the multiple perspectives brought to support this communication. Moreover, some repetition may be needed at various points in time to ensure that a patient's recovery state is not inhibiting their effective understanding and participation in this communication process. ${ }^{[21]}$ While patient satisfaction may be attributable to any number of reasons, effective engagement of a patient in the care processes, as in many MDR implementations, is important and can positively influence a patient's perception of the care provided. In the next section, we will look at the MDR implementation at the hospital through the diffusion of process innovation research and discuss the outcomes observed.

\subsection{Diffusion of MDR as a process innovation}

\subsubsection{About the hospital}

The community hospital in Michigan where the current study was done has been ranked nationally in the top $5 \%$ for clinical experience and has several specialty programs in top 50 in the US. ${ }^{[22]}$ It has recently completed a major multi-million-dollar renovation and expansion to bring comprehensive holistic care supported by advanced technology. Just like many hospitals, it regularly surveys patients after their discharge to understand their satisfaction with the hospital services during their stay, using the HCAHPS survey administered through Press Ganey, an approved vendor. One of the goals of the MDR process innovation is to improve patient satisfaction by engaging patients in their care process while they are in the hospital. The innovation is also expected to contribute to improved patient outcomes, such as reductions in length of stay (LOS) and readmissions.

\subsubsection{The challenges}

In 2014, the hospital realized that patient satisfaction scores were falling short of the expected target range of the top quartile and 50th percentile among HCAHPS survey peer groups. When brainstorming and researching the possible ways to enhance the patients' experience during their hospital stay and improve patient satisfaction levels, the recommendation of using MDR was made.

\section{Phase I OF The MDR implementation: SEPT 2016 TO AuguSt 2017}

Prior research suggests that nurse-led rounding could reduce "disease" or clinical focus and drive everyone's attention to the care-related processes. ${ }^{[23]}$ Hence, the first phase of the MDR implementation was primarily led by nurses. Each MDR team included a nurse, a pharmacist, a patient logistics practitioner (PLP), and a nurse manager. It also included a dietician, patient experience specialist, and a spiritual care provider when needed to support both in-hospital and postdischarge care. In this phase, the hospital decided not to use residents and attending physicians and let this be a nurse-led MDR initiative. A patient experience specialist was specifically tasked with helping support the patient engagement processes within MDR teams.

What makes MDR complex is the number of daily, unitbased, and multi-disciplinary planning discussions a hospital engages in with patients concerning their hospital care - i.e., patient's clinical status, logistical readiness, and follow-up actions required to assure an efficient and safe transition to the next site of care. Such sites range from post-acute facilities to homes equipped with suitable homecare support devices. While post-discharge care services are often a part of the discharge process, these services don't often get enough attention during the patient's stay in a hospital. Also, patients are often not adequately engaged in some of this care planning. ${ }^{[24]}$ This is a first formal attempt by the hospital to connect the in-hospital clinical process with the post-discharge treatment process through patient engagement. The implementation was driven by data from outcomes measures, such as past satisfaction survey data and information gauged from multiple interactions with patients during the rounding activities.

The diffusion of an innovation such as MDR is often influenced by factors such as nature of innovation (process vs. product), adopter characteristics (inherently innovative or not-innovative), and implementation characteristics (e.g., transferability, implementation complexity, and divisibility). ${ }^{[25]}$ Organizations may develop strategies such as support, advocacy, or total commitment to diffuse these innovations into organizations. We next examine how these factors played a role in the diffusion of MDR at the hospital. For the reasons discussed above, MDR is a process innovation for the hospital.

\subsection{Innovation and adopters}

The adopters of the innovation, which include nurses, nurse managers, pharmacists, and others engaged in providing patientcare (see Figure 1) should generally be motivated to adopt any innovation that supports the care process. However, as with any change, they need to be convinced that such innovation is not inconsistent or incompatible with the care they already provide. For instance, some nurses initially viewed the MDR as redundant, time-consuming work or a tool for supervisors to judge their performance. This was quickly addressed by management by making it a nurse-led process and letting nurses use it to get patients engaged in their care plan. 


\subsection{Divisibility}

MDR is not divisible, as all potential team members need to adopt it simultaneously to succeed. One way to handle such complexity is by pursuing an incremental implementation approach (i.e., pilot test the rounding process in some units before expanding into other units) or by having some team members play a role in MDR as opposed to all members. The hospital decided to implement MDR in phases across all units except for hospice patients and patients in isolation, whose needs are quite different from those of the others. MDR processes were introduced and stabilized first in one unit (i.e., a floor on the South unit) before deploying in all other units.

\subsection{Transferability}

This entails better preparation and communication of the MDR practice to enhance the team's and the patient's acceptance of the innovation. The communication must include both the roles and responsibilities of all involved in the MDR practice, as well as the broader goals it is trying to accomplish. Goals such as improving patientcare, increasing patient engagement, and ensuring safe transition to the next level of care were clearly identified and communicated to the team. Also, a few key questions of the HCHAPS patient satisfaction survey were identified as selective metrics to assess the impact of MDR by the care experience team. This team included both the specialist in patient experience as well as some senior management staff, including clinical medical informatics officers. This team educated, supported, monitored, and counselled MDR teams as the MDR process evolved to influence the selected metrics.

In terms of roles, each MDR team member plays an important part to achieve the desired patient outcomes. The nurse's role includes greeting the patient and providing a brief overview of their current medical status. The nurse manager focused on practice excellence during MDR by motivating and educating the team. The PLP (or case manager) initiates, coordinates, and implements necessary procedures and plans for patient interventions. The pharmacist reviews and reconciles medication at the time of admission and transfer and answers any medication related questions during MDR. Based on a patient's clinical information, the MDR team outlines daily medical milestones and sets an anticipated discharge date in consultation with the patient. Similarly, the roles of other team members (e.g., dietician and spiritual mentor) are clearly outlined and brought in when needed. The responsibilities of the team were established by structuring the process of team engagement with the patient. These include:
- Spending about 4-5 minutes with each patient.

- Having a daily schedule for the meeting between 10:00 a.m. and noon. This allows for PLPs to have enough time to review each patient's information ahead of time, and it also helps family members to schedule their visits to ask questions about the patient's progress and plan of care.

- Discussing patientcare plan in front of the patient, even if team members feel uncomfortable discussing it due to differences in language/terminology, as it is important for the patient to understand and ask questions.

- Maintaining eye contact with the patient and avoiding use of any computer screens when engaging in a dialog, which are considered critical for developing intimacy. ${ }^{[26]}$

- Knocking on the door before entering and using the patient's name or initials, so as to support patient privacy, demonstrate respect and develop a relationship with the patient.

\subsection{Implementation complexity}

Given the breadth (number of people involved in the MDR practice) and depth (diverse units) involved in the process change, MDR implementation is certainly a complex endeavor. Since the hospital decided to implement the MDR practice in phases in all its clinical units except hospice and ICU units, hospital administration needed a proactive approach to continually monitor the implementation practice and take any corrective actions as needed. This required an advocacy approach for diffusing the innovation. ${ }^{[25]}$ The advocacy approach called for making a nurse the leader of the MDR practice, using a structured process with well-defined roles and responsibilities (transferability), and developing an active feedback mechanism to address any concerns patients expressed rather than wait for satisfaction data on selected metrics. This feedback mechanism included 30, 60, and 90day surveys that included post rounding patient experience as well as feedback from MDR team members. The composition of MDR team and the underlying information used in influencing the MDR process is shown in Figure 1. The next section discusses the results of the first phase of the MDR implementation.

\subsection{Results from Phase I of the MDR implementation}

To assess the impact of MDR on patient care and adapt the MDR process, the hospital used multiple ways of receiving patient feedback. Results from HCHAPS surveys filled by patients post-discharge was an important feedback tool to gather patient assessment on certain key metrics. In addition, some of the same metrics are used while a patient is in the 
hospital to get quick feedback so the MDR process can be improved using a set of questions shown in Table 1 after 30, 60 and 90-day rounds.

These questions were adapted from the HCHAPS survey questions on nurse communication, discharge information and transition of care. Table 2 shows how the key goals from HCHAPS questions were related to the goals of the
IDR team. While the questions used in Table 1 were worded differently for the easy understanding, they sought to assess the value IDR team provided in a patient's post-discharge care plans as well as how they are treated them while they are in the hospital. In fact, the bottom row of the Table 2 shows how the engagement with patients should lead to the last column - educating the patients on what they need to do when they leave the hospital.

\section{Patient Centered Process Innovation}

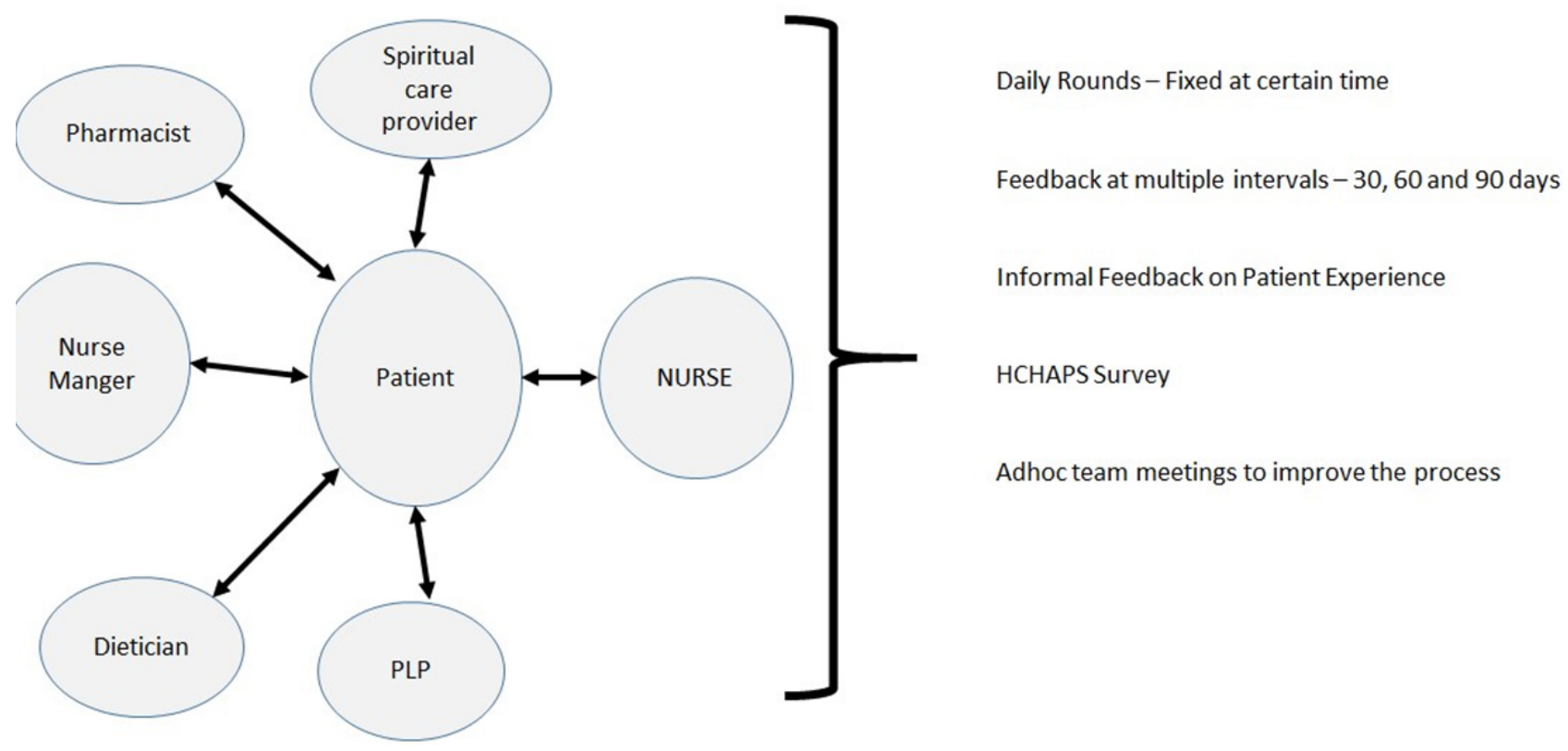

Figure 1. MDR team members and information used to improve MDR process

Table 1. 30, 60 and 90-day rounding questions

\begin{tabular}{lll}
\hline 30 Day Survey & 60 Day Survey & 90 Day Survey \\
\hline $\begin{array}{l}\text { Has your care team been in the room to } \\
\text { engage you in Multidisciplinary } \\
\text { Rounding? }\end{array}$ & $\begin{array}{l}\text { Did you feel included in the conversation } \\
\text { (during MDR's)? }\end{array}$ & $\begin{array}{l}\text { During Multidisciplinary rounds, did the } \\
\text { care team introduce themselves? }\end{array}$ \\
$\begin{array}{lll}\text { Did you feel that this was beneficial to } \\
\text { you and/or your family member(s)? }\end{array}$ & $\begin{array}{l}\text { Did you feel that this was beneficial to } \\
\text { you and/or your family member(s)? }\end{array}$ & $\begin{array}{l}\text { Did the care team engage you in your plan } \\
\text { of care or goals for the day in a way that } \\
\text { was clear to you? }\end{array}$ \\
$\begin{array}{ll}\text { Did you feel comfortable to express any } \\
\text { concerns to the care team? }\end{array}$ & $\begin{array}{l}\text { Where you gave the opportunity to ask } \\
\text { questions? }\end{array}$ & $\begin{array}{l}\text { Do you know your Estimated Discharge } \\
\text { Date (EDD)? If this date has passed, have } \\
\text { you been informed of the change? }\end{array}$ \\
$\begin{array}{ll}\text { Is there anything that we can do better? } \\
\text { Is there anything that we can do better (as }\end{array}$ & $\begin{array}{l}\text { Do you feel informed of your discharge } \\
\text { alans? }\end{array}$ \\
\hline
\end{tabular}


Table 2. Mapping of HCHAPS goals to goals from 30, 60 and 90 rounds

\begin{tabular}{|c|c|c|c|c|c|c|c|}
\hline & $\begin{array}{l}\text { Key Communication } \\
\text { Goals from HCHAPS } \\
\text { Survey }\end{array}$ & IDR & 30-Day & 60-Day & 90-Day & & \\
\hline $\begin{array}{l}\text { Nurse } \\
\text { communication }\end{array}$ & $\begin{array}{l}\text { Courtesy, respect; } \\
\text { listening, providing } \\
\text { easy explanation }\end{array}$ & $\begin{array}{l}\text { Included patients in } \\
\text { discussion in a } \\
\text { personalized manner }\end{array}$ & & & & $\begin{array}{l}\text { Show } \\
\text { empathy }\end{array}$ & \\
\hline $\begin{array}{l}\text { Discharge } \\
\text { information }\end{array}$ & $\begin{array}{l}\text { Sought information on } \\
\text { help needed and } \\
\text { provided symptoms to } \\
\text { look for }\end{array}$ & $\begin{array}{l}\text { Care related goals } \\
\text { and plans provided } \\
\text { are beneficial to you } \\
\text { and family members }\end{array}$ & $\begin{array}{l}\text { Engagement } \\
\text { beneficial and } \\
\text { comfortable }\end{array}$ & $\begin{array}{l}\text { Felt included and } \\
\text { comfortable to } \\
\text { interact }\end{array}$ & $\begin{array}{l}\text { Provided } \\
\text { information on } \\
\text { what to do and } \\
\text { expect in a } \\
\text { personalized }\end{array}$ & $\begin{array}{l}\text { Ask } \\
\text { questions }\end{array}$ & $\begin{array}{l}\text { Educated patients } \\
\text { on what to do and } \\
\text { how once they } \\
\text { leave hospital }\end{array}$ \\
\hline \multirow[t]{2}{*}{$\begin{array}{l}\text { Transition of } \\
\text { care }\end{array}$} & $\begin{array}{l}\text { Understood family and } \\
\text { care giver preferences } \\
\text { and explained their } \\
\text { responsibilities }\end{array}$ & $\begin{array}{l}\text { Made you } \\
\text { comfortable to } \\
\text { express concerns and } \\
\text { ask questions }\end{array}$ & & & manner & $\begin{array}{l}\text { Provide } \\
\text { answers }\end{array}$ & \\
\hline & & & Beneficial & Comfortable & Useful & & \\
\hline
\end{tabular}

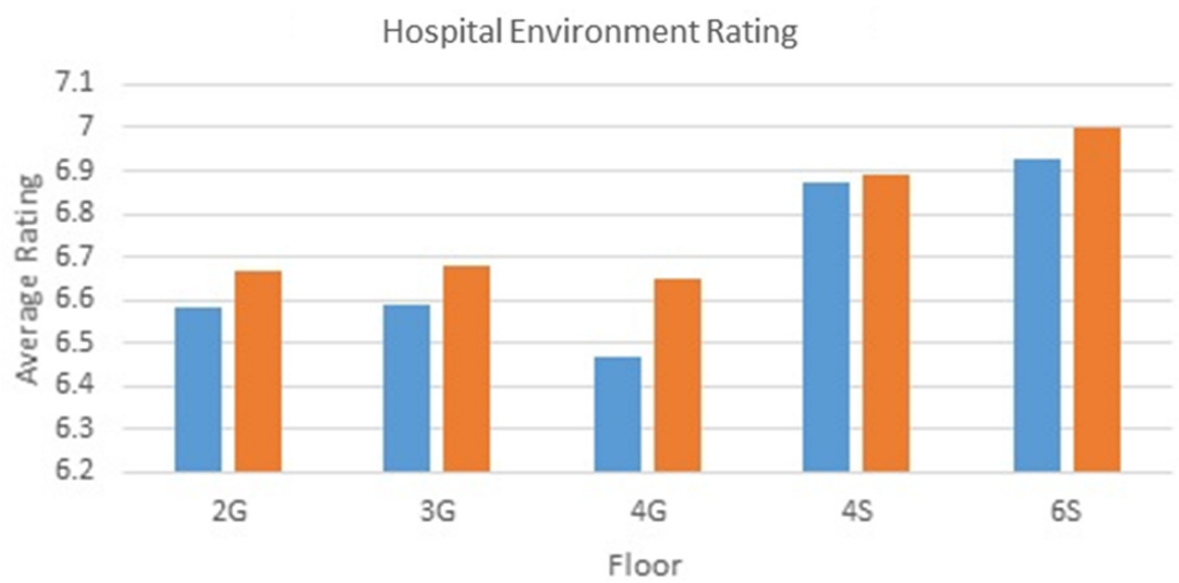

E BeforeMDR After MDR

Figure 2. Hospital environment rating before and after MDR implementation (by floor)

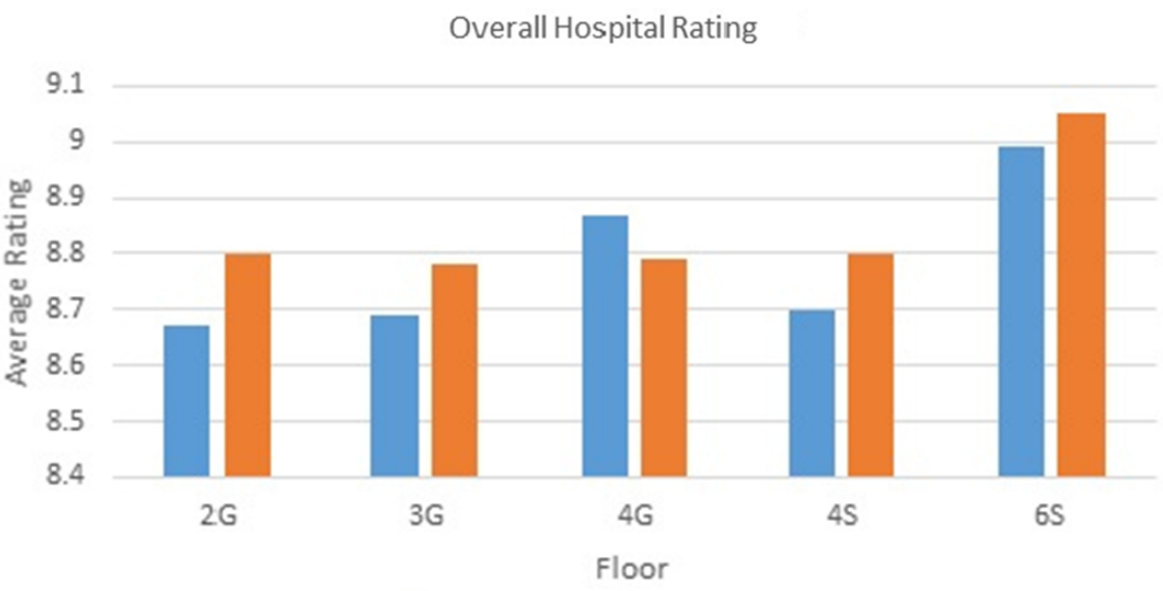

BeforeMDR a After MDR

Figure 3. Overall hospital rating before and after MDR implementation (by floor) 


\subsubsection{Feedback from patient satisfaction data of HCHAPS}

Patient satisfaction data from several floors, those that serve in-patient rehab, cardiology non-interventional CHF, oncology, medical/surgical, and neurology were analyzed (sample size $=1,984)$. While the data has not shown any statistically significant improvement in patient satisfaction scores, there are some encouraging signs. The average rating of the hospital environment increased in all units after implementing MDR (see Figure 2), and the overall hospital rating has shown improvement in all floors except one (see Figure 3).

\subsubsection{Feedback from data collected at the bedside}

Patient experiences regarding MDR were captured at the bedside at three time periods - i.e., 30, 60, and 90 days. These experiences included the survey questions as well as a few informal yes/no questions to allow patients to make general comments. The face validity of these questions was verified by the care experience team before adminstering these questions and, as shown in Table 1, tried to capture the essence of what is being measured: showng empathy and answering questions patients and family have. The 30-day surveys were completed by 57 patients, and 60-day surveys were completed by 94 . An insufficient number of 90-day surveys were collected, as the process went through a change that is discussed in the next section.

The survey results again attest to the positive benefits of MDR implementation. For instance, when asked if they felt MDR rounds were beneficial to them and their families, about $84 \%$ of patients in the 30-day survey and about $91 \%$ of patients in the 60-day survey answered in the affirmative. About $87 \%$ of patients sampled in the 30-day survey indicated that they felt free and open to express their concerns to the team. In the 60 -day survey, about $90 \%$ of patients indicated that they felt included in the conversation and that they were given an opportunity to ask questions. These questions are simple yes/no questions.

The patient comments in the surveys also indicate that they generally felt quite positive about MDR. Some pertinent comments are shown in the Table 3 below.

Table 3. Patient comments at different time periods after MDR implementation

\begin{tabular}{|c|c|c|}
\hline 30-day Comments & 60-day Comments & 90-day Comments \\
\hline $\begin{array}{l}\text { It felt good to hear what was keeping me } \\
\text { here }\end{array}$ & $\begin{array}{l}\text { I like it better when wife is here. She gave } \\
\text { some information I forgot }\end{array}$ & Very informative \\
\hline $\begin{array}{l}\text { You all make me feel like my opinion } \\
\text { counts }\end{array}$ & $\begin{array}{l}\text { Gave input from family. (They) Listened } \\
\text { to our concerns }\end{array}$ & I probably talked more than they did \\
\hline $\begin{array}{l}\text { Love the whole team coming in. Nice to } \\
\text { know who's who }\end{array}$ & $\begin{array}{l}\text { As a family member, it's good to confirm. } \\
\text { Very nice to have pharmacist standing in } \\
\text { room }\end{array}$ & $\begin{array}{l}\text { Spiritual considerations taken into } \\
\text { consideration. Loved having elderly lady } \\
\text { come to room for prayer }\end{array}$ \\
\hline $\begin{array}{l}\text { This hospital is good taking the time to } \\
\text { explain things }\end{array}$ & $\begin{array}{l}\text { Explain team's goals as a plan for the day. } \\
\text { Explain purpose better }\end{array}$ & \\
\hline \multicolumn{3}{|l|}{$\begin{array}{l}\text { I got the chance to see all you guys who } \\
\text { work with me }\end{array}$} \\
\hline \multicolumn{3}{|l|}{$\begin{array}{l}\text { Family shared information they wouldn't } \\
\text { have known }\end{array}$} \\
\hline \multicolumn{3}{|l|}{ Yes, they made me feel engaged } \\
\hline I don't think I'm ready to go home & & \\
\hline
\end{tabular}

I feel you all are spoiling me too much

Patients also provided some constructive comments in the 30-day survey for improving the MDR process - e.g., "Have a writing pad in the room so patient can write down questions for the doctor and others can leave notes if asleep".
Also noted was a concern among patients that the number of people in the MDR team intimidated them to ask questions easily. Taking into account these comments, along with the hospital's need to proactively educate patients and their fam- 
ily members on the care plans inside the hospital and what they need to do after they leave to self-manage their health, a variation of the MDR process was initiated in Phase II.

\section{Phase II: Implementation of the MDR PROCESS: OCTOBER 2017 TO PRESENT}

Hospitals have a unique opportunity to use their engagement with patients while they are in the hospital to help empower patients to self-manage their healthcare post-discharge by educating them all through their care process. This can help patients adhere to post-discharge care instructions, thus potentially resulting in reduced readmission costs as well as improved patient satisfaction. For example, patients in an ICU used diaries to create a narrative of their experience and evaluate their recovery, so that they could share it with family members in support of family-centered care. ${ }^{[28]}$ Similarly, enhanced patient education was cited as critical to reduce readmissions. ${ }^{[29]}$ Enhancing patient education is cited as critical to reduce readmissions. ${ }^{[28]}$

Management research alludes to the relationship between training/education of individuals and their psychological empowerment in organizations. ${ }^{[29]}$ Such empowerment is felt in terms of meaning (fit between one's work and beliefs, values and behaviors), competence (self-efficacy with respect to one's work), self-determination (choice in regulating one's actions), and impact (the ability to influence work outcomes). ${ }^{[30]}$ It is therefore reasonable to expect that educating patients in an MDR setting can contribute to their psychological empowerment by providing them meaning (e.g., how the work of different caregivers fit together), competence (e.g., enhancing their self-efficacy to take care of their own treatment plans post discharge), self-determination (e.g., having a higher sense of choice in their treatment trajectory during hospital stay and beyond), and impact (e.g., a better sense of what to expect in terms of clinical outcomes). These observations and MDR team feedback led the hospital to alter the focus of the MDR process in three important ways for Phase II implementation.

Cohort rounding was introduced to reduce avoidable LOS and educate patients in care processes post-discharge. The cohort rounding is led by a physician and/or a mid-level provider of patients under the care of a physician team. It includes the assigned nurse, case manager, and a representative from the pharmacy team. While the focus of MDR in Phase I was to improve patient satisfaction, the focus in Phase II has a few key benefits, which can also have the potential for improved patient satisfaction. By having a physician and a nurse as part of the team, clinical issues can be addressed quickly. By including pharmacy representation, some of the medication reconciliation issues can be addressed along with prescription follow-up post discharge. Rounding occurring at a fixed time each day helps patients write down their questions, and fewer team members can lead to less patient intimidation.

A folder called "My Discharge Instructions and Health Care Plan" was provided to patients as they arrived to their room. The folder includes:

- A Discharge Readiness Checklist

- MDR, what is it and who are the key players

- Space to write down questions for the doctor, their current medications

- Section for discharge paperwork

- Section to set up follow-up appointments after they leave the hospital

- Additional resource \& education materials

Bringing clarity to the discharge plan and providing explanations to the patients and their family members about the care being provided at various points in time can help educate patients on what they need to do from a clinical perspective post-discharge. For example, if the hospital takes the initiative in follow-up appointments for the patient before they are discharged, it can avoid delays in connecting with the patient's PCP. Also, trying to arrange transportation for the patient for follow-up appointments can show empathy and empower patients to take ownership of their healthcare follow-up and encourage them to keep their appointments or call to cancel or reschedule if they can't.

Education of the care team: Each member of the team is required to watch a video on how the new rounding process works, with team members given flexibility on when and where to watch the video. The video, narrated by nurse educators with trained inpatient staff, shows how the rounding staff can show the patient where in the folder is, the care plan they are following and the services that are delivered. This reduces uncertainty and makes the folder/document come to life in terms of the expectations of the patients as well as the care staff. It encourages patients to see the document as something they can refer to after they leave the hospital for information such as prescription dosage, nutritional guidance, rehabilitation exercise routines, etc.

The results from this modified rounding thus far have shown improvements in unavoidable LOS and may over time lead to improvement in patient satisfaction. However, educating patients to self-manage their health should have a positive impact given that a small MDR team is proactively mentoring 
patients by answering questions, educating them on their role post-discharge, and providing an immediate resolution to any "incidents" that need to be. To this end, the hospital has implemented two different systems, and these are discussed in Table 4 below.

Table 4. Technology to support MDR teams address patient concerns

Track data from rounding within performance dashboards so, in real time, red to green colors can show that rounding has occurred.

An app was developed internally, so the nurse manager can ask a series of questions to the patient and be able to do live service recovery based on the responses they receive from the patient. This is done on an iPad during RN manager rounds.

A newly developed system provides a summary of key elements from the patient chart and other documentation by RN, Physicians, Pharmacy, etc. The goal is to capture items that assist the hospital in patient satisfaction such as "Patient favorites things list" and document watch list items related to the patient condition that all provider should be o be aware of (not necessarily documented in patient chart).

\section{Discussion}

The hospital generally followed a standard protocol in the rounding practice - e.g., each member introduced himself/herself, communicated their respective role, shared their knowledge, and explained how this affects the patient's plan of care. Having patient's family member present during an MDR team visit was found to be valuable, as it allowed them to seek clarifications to any additional questions they might have. Addressing patients by their names, maintaining eye contact with the patients, and minimizing any side conversations between members all seem to help improve patient experience. While the impact of MDR on patient satisfaction survey outcomes has not been fully established here, the use of MDR and bedside interactions are consistent with the Institute of Medicine recommendation that call for educating healthcare professionals on patient-centric healthcare delivery using multidisciplinary teams ${ }^{[27]}$ for effective outcomes. One of these outcomes is the education of patients on the care provided inside the hospital so that they can take some of this knowledge to care for themselves after they leave the hospital. While the results thus far have not shown a significant impact on patient satisfaction scores, it is important to understand that MDR rounding has many other advantages as discussed in this paper. Besides the education of patients and the care delivery team about shared goals in patient-centered care, it is designed to bring patients and family members into the care team to develop a shared understanding of the roles and responsibilities of all involved in the care delivery process. Such a broader lens can only help a patient after they leave the hospital.

\section{CONClusions AND limitations}

The current evidence regarding the effectiveness of MDR in improving patient satisfaction and pre-discharge care planning, while encouraging, needs further analysis. Also, the results relate to MDR implementation at one Michigan community hospital and are not immediately generalizable to other hospital settings. This study is exploratory in nature, and work is on-going to fully understand how the doctornurse led process to educate patients will lead to a broader set of positive outcomes besides a single metric such as patient satisfaction.

While patient satisfaction was the primary motivator for introducing MDR, the study does show that an intimate approach that brings care teams working closely with patents and family members can have many positive outcomes besides patient satisfaction as measured by HCHAPS. One example is understanding patient ecosystem post discharge to tailor care plans to reflect this reality (e.g., arranging transportation if a patient has difficulty getting to an appointment). Also, noticing critical issues faced by a patient while in the hospital and addressing these quickly can help potentially reduce complications and streamline care processes.

\section{CONFlicts OF INTEREST Disclosure}

The authors declare they have no conflicts of interest. 


\section{REFERENCES}

[1] Hibbard JH, Stockard J, Tusler M. Hospital Performance Reports: Impact On Quality, Market Share, And Reputation. Health Affairs. 2005; 24(4): 1150-1160. PMid: 16012155. https ://doi.org/10 $.1377 /$ hlthaff .24 .4 .1150

[2] Tsai TC, Orav EJ, Jha AK. Patient Satisfaction and Quality of Surgical Care in US Hospitals. Annals of Surgery. 2015; 261(1): 2 8. PMid: 24887985. https://doi.org/10.1097/SLA.000000 0000000765

[3] Beaudin CL, Lammers JC, Pedroja AT. Patient perceptions of coordinated care: the importance of organized communication in hospitals. Journal for Healthcare Quality. 1999; 21(5): 18-23. PMid: 10620880. https://doi.org/10.1111/j.1945-1474.1999.tb00985.x

[4] Huppertz JW, Carlson JP. Consumers' Use of HCAHPS Ratings and Word-of-Mouth in Hospital Choice. Health Services Research. 2010; 45(6 Pt 1): 1602-1613. PMid: 20698896. https ://doi .org/10.1 $111 / j .1475-6773.2010 .01153 . x$

[5] Thorne KMD, Andersson-Gare BP, Hult HP, et al. Co-Producing Interprofessional Round Work: Designing Spaces for Patient Partnership. Quality Management in Health Care April/June. 2017; 26(2): 70-82. PMid: 28375953. https ://doi .org/10.1097/QMH. 0000 000000000133

[6] Gonzalo JD, Wolpaw DR, Lehman E, et al. Patient-centered interprofessional collaborative care: factors associated with bedside interprofessional rounds. Journal of General Internal Medicine. 2014; 29(7): 1040-1047. PMid: 24615186. https://doi.org/10.1007/s116 06-014-2817-x

[7] O'Leary KJ, Killarney A, Hansen LO, et al. Effect of patient-centred bedside rounds on hospitalised patients' decision control, activation and satisfaction with care. BMJ Quality \& Safety. 2016; 25(12): 921928. PMid: 26628552. https ://doi.org/10.1136/bmjqs-201 5-004561

[8] Commision TJ. Hospital: 2018 National Patient Safety Goals. National Patient Safety Goals: The Joint Commission on Accreditation of Healthcare Organizations. 2018; 2.

[9] Weinstein RS, Brandt BF, Gilbert JH, et al. Bridging the quality chasm: interprofessional teams to the rescue? The American Journal of Medicine. 2013; 126(4): 276-277. PMid: 23398952. https://doi.org/10.1016/j.amjmed.2012.10.014

[10] Gurses AP, Xiao Y. A systematic review of the literature on multidisciplinary rounds to design information technology. Journal of the American Medical Informatics Association. 2006; 13(3): 267-276 PMid: 16501176. https://doi.org/10.1197/jamia.M1992

[11] Ryan L, Scott S, Fields W. Implementation of Interdisciplinary Rapid Rounds in Observation Units. Journal of Nursing Care Quality. 2017. https://doi.org/10.1097/NCQ.0000000000000250

[12] Gausvik C, Lautar A, Miller L, et al. Structured nursing communication on interdisciplinary acute care teams improves perceptions of safety, efficiency, understanding of care plan and teamwork as well as job satisfaction. Journal of Multidisciplinary Healthcare. 2015; 8: 33 . PMid: 25609978. https://doi .org/10.2147/JMDH.S72623

[13] Cornell P, Townsend-Gervis M, Vardaman JM, et al. Improving situation awareness and patient outcomes through interdisciplinary rounding and structured communication. Journal of Nursing Administration. 2014; 44(3): 164-169. PMid: 24531289. https: //doi.org/10.1097/NNA.0000000000000045

[14] Townsend-Gervis M, Cornell P, Vardaman JM. Interdisciplinary rounds and structured communication reduce re-admissions and improve some patient outcomes. Western Journal of Nursing Research. 2014; 36(7): 917-928. PMid: 24658290. https ://doi.org/10.1 $177 / 0193945914527521$
[15] Tripathi S, Arteaga G, Rohlik G, et al. Implementation of PatientCentered Bedside Rounds in the Pediatric Intensive Care Unit. Journal of Nursing Care Quality. 2015; 30(2): 160-166. PMid: 25503373. https://doi.org/10.1097/NCQ.0000000000000107

[16] Fernandez R, Tran DT, Johnson M, et al. Interdisciplinary communication in general medical and surgical wards using two different models of nursing care delivery. Journal of Nursing Management. 2010; 18(3): 265-274. PMid: 20546466. https://doi.org/10.1 $111 / j \cdot 1365-2834.2010 .01058 \cdot x$

[17] Vyt A. Interprofessional and transdisciplinary teamwork in health care. Diabetes/Metabolism Research and Reviews. 2008; 24(S1): S106-S109. PMid: 18393329. https://doi.org/10.1002/dmrr .835

[18] Zwarenstein M, Goldman J, Reeves S. Interprofessional collaboration: effects of practice-based interventions on professional practice and healthcare outcomes. Cochrane Database Syst Rev. 2009; 3(3). PMid: 19588316. https://doi.org/10.1002/14651858 .CD000072.pub2

[19] Olivere RM. Bringing the Patient to the Center: Implementing an Interdisciplinary Rounding Approach in the Labor and Delivery Setting. Journal of Obstetric, Gynecologic, \& Neonatal Nursing. 2013; 42(s1): S53-S53. https://doi.org/10.1111/1552-6909.12128

[20] Reimer N, Herbener L. Round and round we go: rounding strategies to impact exemplary professional practice. Clinical Journal of Oncology Nursing. 2014; 18(6): 654. PMid: 25305021. https: //doi.org/10.1188/14.CJON.18-06AP

[21] Anonymous. Delivering Great Care: Engaging Patients and Families as Partners. Improvement Stories. 2012. Available from: http://www.ihi.org/resources/Pages/ImprovementSto ries/DeliveringGreatCareEngagingPatientsandFamilie sasPartners .aspx

[22] Detroit W. Eight metro Detroit hospitals stand out among nation's best. 2013. Available from: https: //www .wxyz.com/news/report-eight-metro-detroit -hospitals-stand-out-among-nations-best

[23] Senot C, Chandrasekaran A, Ward PT. Collaboration between service professionals during the delivery of health care: Evidence from a multiple-case study in US hospitals. Journal of Operations Management. 2016; 42: 62-79. https://doi.org/10.1016/j.jom. 20 16.03 .004

[24] Wong ELY, Yam CHK, Cheung AWL, et al. Barriers to effective discharge planning: a qualitative study investigating the perspectives of frontline healthcare professionals. BMC Health Services Research. 2011; 11: 242-242. PMid: 21955544. https ://doi .org/10.118 6/1472-6963-11-242

[25] Agarwal R, Tanniru M, Wilemon D. Assimilating information technology innovations: strategies and moderating influences. IEEE Transactions on Engineering Management. 1997; 44(4): 347-358. https://doi.org/10.1109/17.649864

[26] Berman AC, Chutka DS. Assessing effective physician-patient communication skills: "Are you listening to me, doc?". Korean Journal of Medical Education. 2016; 28(2): 243-249. PMid: 26913771. https://doi.org/10.3946/kjme.2016.21

[27] Greiner AC, Knebel E, eds. Health professions education: A bridge to quality. Washington, DC: National Academic Press; 2003.

[28] Blair KTA, Eccleston SD, Binder HM, et al. Improving the Patient Experience by Implementing an ICU Diary for Those at Risk of Post-Intensive Care Syndrome. Journal of Patient Experience. 2017; 4(1): 4-9. PMid: 28725854. https ://doi .org/10.1177/237437 3517692927

[29] Hume K, Tomsik E. Enhancing Patient Education and Medication Reconciliation Strategies to Reduce Readmission Rates. Hos- 
pital Pharmacy. 2014; 49(2): 112-114. PMid: 24623862. https: //doi.org/10.1310/hpj4902-112

[30] Spreitzer GM. Taking stock: A review of more than twenty years of research on empowerment at work. Handbook of Organizational Behavior. 2008; 1: 54-72. https://doi.org/10.4135/978184 9200448.n4

[31] Greiner AC, Knebel E, eds. Health professions education: A bridge to quality. Washington, DC: National Academic Press; 2003. 